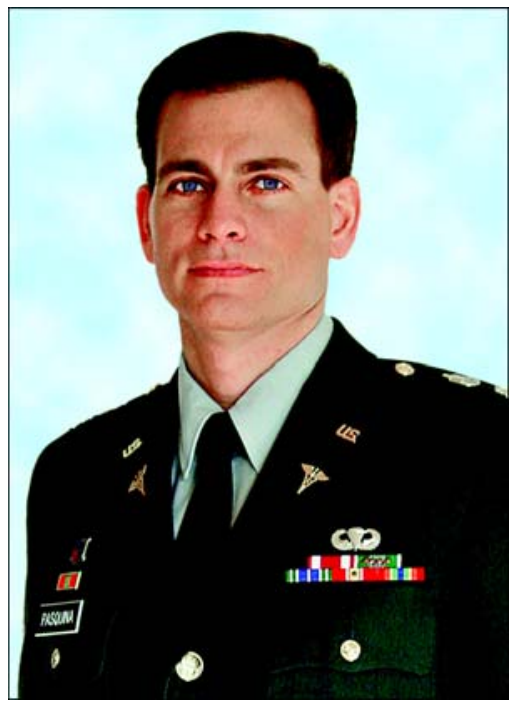

Paul F. Pasquina, MD

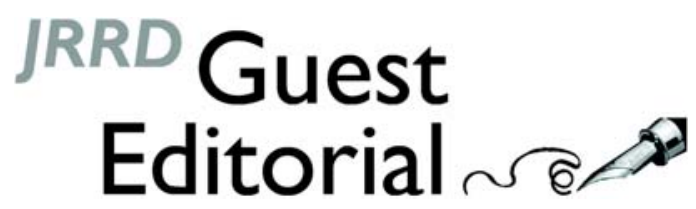

\title{
National Disabled Veterans Winter Sports Clinic
}

Participation in sports and recreational activities can significantly effect an individual's well-being and overall quality of life. A regular exercise program strengthens the musculoskeletal system, improves cardiovascular function, and helps prevent and treat medical conditions such as diabetes mellitus, hypertension, and obesity [1-3]. Participation in sports also decreases symptoms of mild depression, promotes well-being, and improves social skills [4]. Within the disabled veteran community, the benefits of sports and exercise may be exponential. By improving physical condition, function, and psychological well-being, intensive sports and exercise may greatly improve the long-term prognosis for patients with disabilities.

Healthcare practitioners should be aware of the opportunities for sports and recreational activities available to their patients. Today, numerous opportunities exist for individuals with disabilities, although many are still hampered by barriers such as limited access and lack of awareness. The National Disabled Veterans Winter Sports Clinic is one example of an event that has been successful in breaking down these barriers, thanks to its numerous public and private supporters and the leadership of its organizer Santo "Sandy" Trombetta (pictured below).

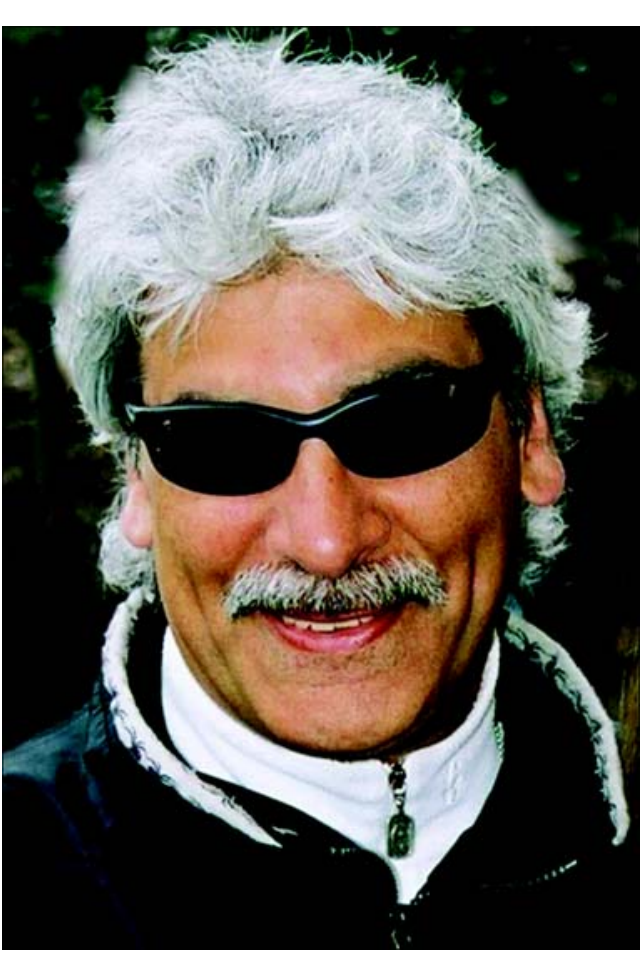

The National Disabled Veterans Winter Sports Clinic is currently the largest rehabilitative program of its kind in the world and includes adapted physical activities as well as workshops and educational sessions that aid in the rehabilitation of severely disabled veterans. Activities such as Alpine and Nordic skiing, snowmobiling, scuba diving, fly-fishing, wheelchair golf, wheelchair self-defense, rock wall climbing, sled hockey, trapshooting, blues harmonica instruction, dogsledding, goal ball for the visually impaired, wheelchair fencing, and amputee volleyball are only a small number of the adapted sports and activities that have been offered over the past 20 years.

Set in recent years in Snow Mass, Colorado, near Aspen, the clinic targets disabled veterans with spinal cord injuries, amputations, neurological disorders, and visual impairments to improve physical well-being, mental 
health, and self-esteem with the ultimate goal of enabling veterans with profound disabilities to rediscover life after disability. The National Disabled Veterans Winter Sports Clinic helps veterans achieve higher levels of self-actualization and empowers them to live a happier, healthier, and more productive lifestyle.

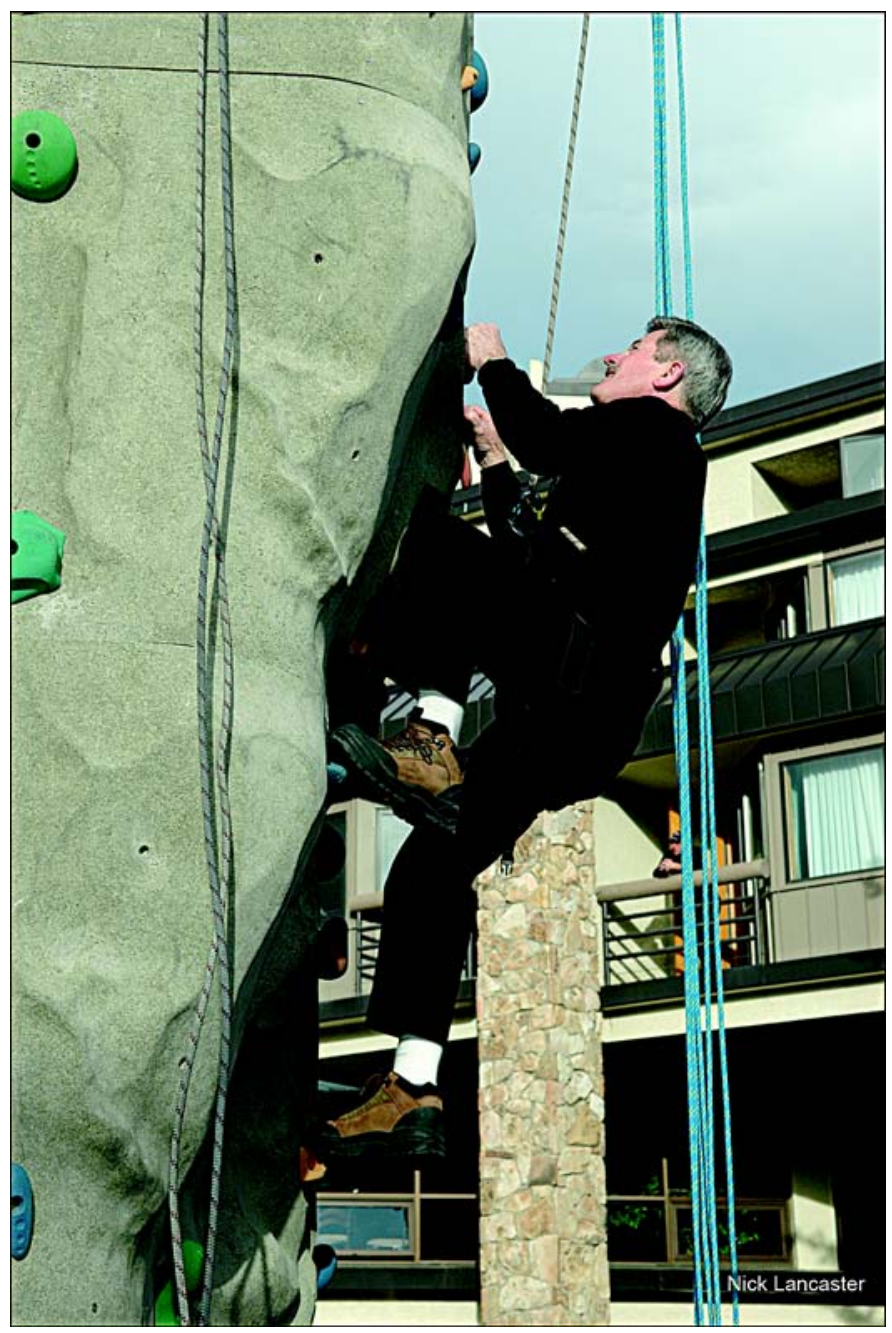

It is no wonder that the program has such a beneficial effect on its participants. Many studies have demonstrated the benefits of exercise on patients with disabilities and have found associated improvements in physical and psychological wellness. For example, one study of individuals with multiple sclerosis found a direct correlation between improvement in exercise ability and psychological wellbeing [5]. While determining what aspect of exercise may be causing these improvements is difficult,

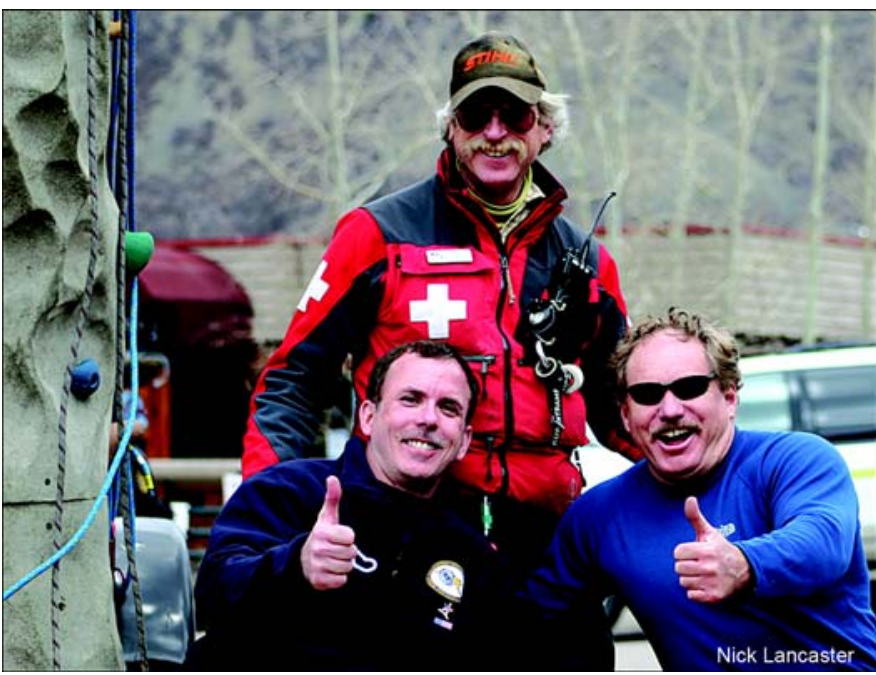

some researchers have postulated that they are directly related to improvements in chronic pain and fatigue [6]. In a comparison study of wheelchair athletes and nonathletes, athletes scored far lower than nonathletes in depression when administered a Profile of Mood States [7]. Patients who exercise may also experience positive influences from the environment created through cooperative sports. Being surrounded by their peers, interacting with others, and witnessing their own improvement in abilities may all play a vital role. In addition, patients are often uplifted when they are able to return to activities that they participated in prior to their injury or illness. No matter what the reason, sports and recreation are clearly a vital part of the lives of many persons with disabilities [8].

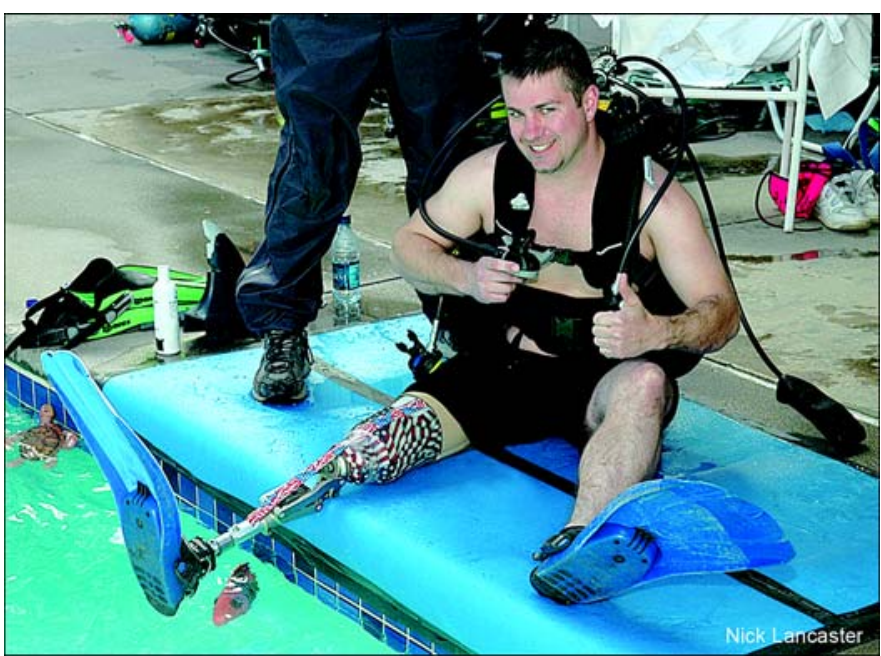




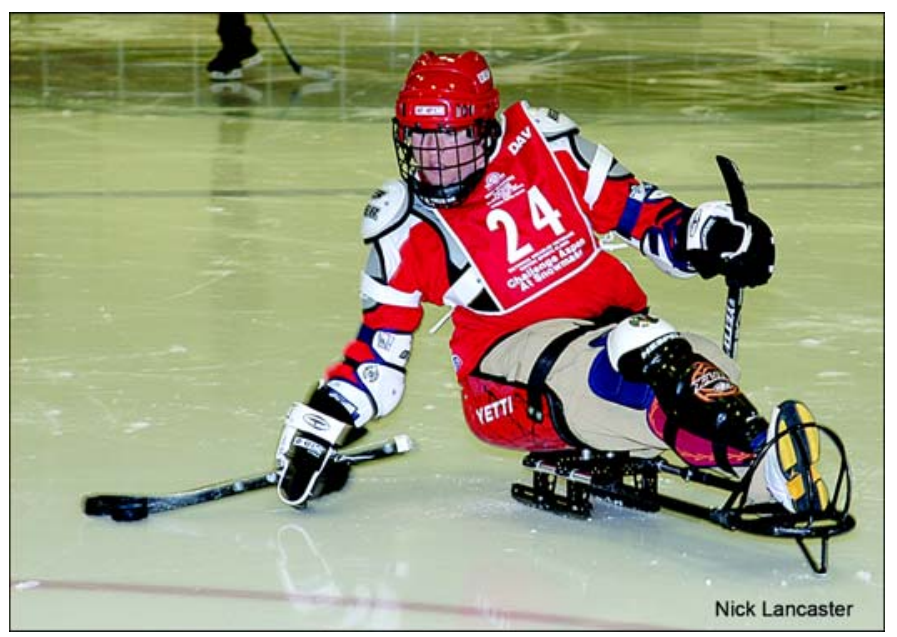

Despite the apparent evidence that sports and exercise can help improve the lives of individuals with disabilities, the National Disabled Veterans Winter Sports Clinic was not readily accepted by conventional healthcare philosophy when it was introduced in 1987. The concept of using challenging, adaptive activities in an outdoor winter environment was so new and outside of the traditional medical philosophy that many doubted it could be successful. The logistical aspects alone of transporting, lodging, feeding, and caring for severely injured veterans in a winter environment were thought by many to be insurmountable, much less teaching them how to participate in winter sports. Fortunately, through creative problem solving, hard work, and force of will, barriers were not just overcome, they were literally torn down.

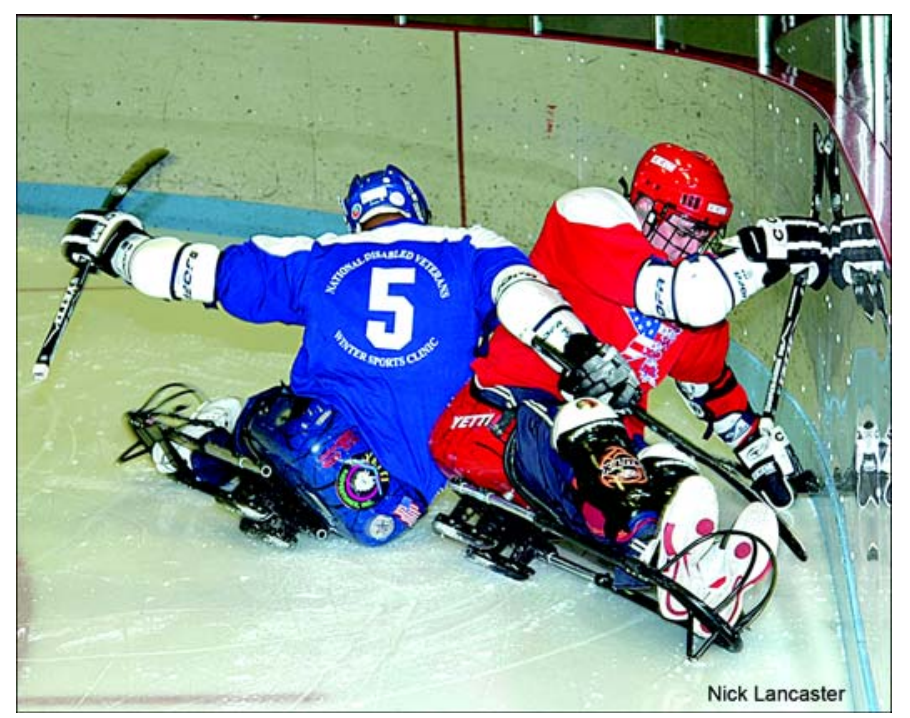

Today more than 350 disabled veterans arrive each year at the National Disabled Veterans Winter Sports Clinic, 30 percent of whom are first-time participants. Individuals enroll through their local Department of Veterans Affairs (VA) facility and arrive on the mountain from all regions within the United States. The event staff organizes and arranges all meals, lodging, and transportation, including shuttle services to all scheduled activities that have accessibility equipment specially designed to help the veterans negotiate the winter environment. Buses are adapted for wheelchairs, and special loading chairs are used to transfer veterans in wheelchairs in and out of buses and airplanes. Volunteers are trained in

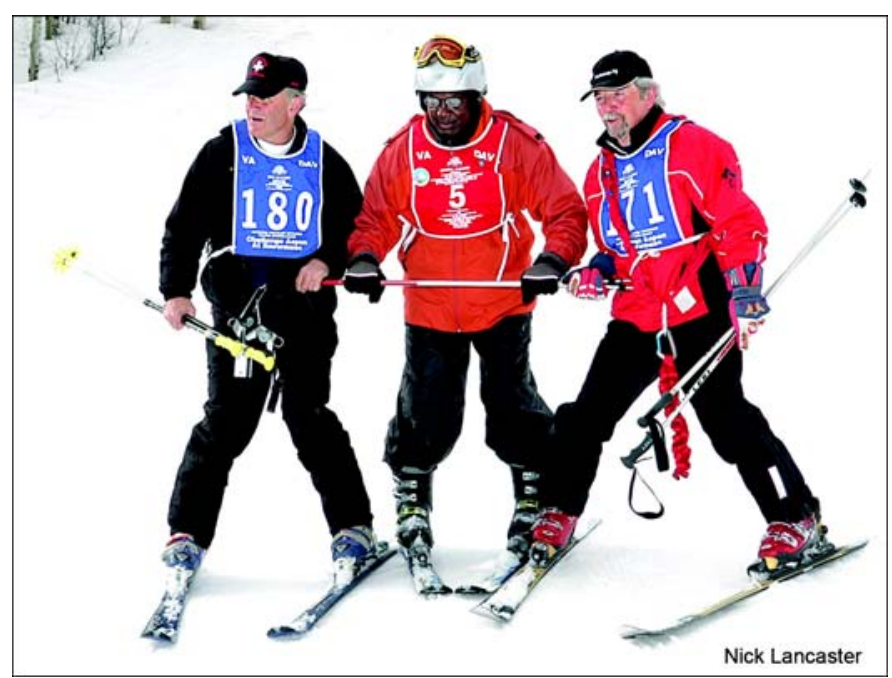

every aspect of the clinic to guarantee that all the needs of the disabled veterans are met. The clinic keeps up with technology as technology keeps up with demand. New discoveries are made every year that improve the lives of individuals with disabilities, and this new technology has helped individuals to not only participate but also excel in a variety of sports, such as skiing, racing, golf, basketball, and even mountain climbing [9].

Since the first Winter Sports Clinic, it has become obvious that this form of therapy can meet the physical and psychosocial needs of the most seriously disabled individuals, as well as motivate individuals who may not respond to more traditional forms of therapy. Although logistical challenges 


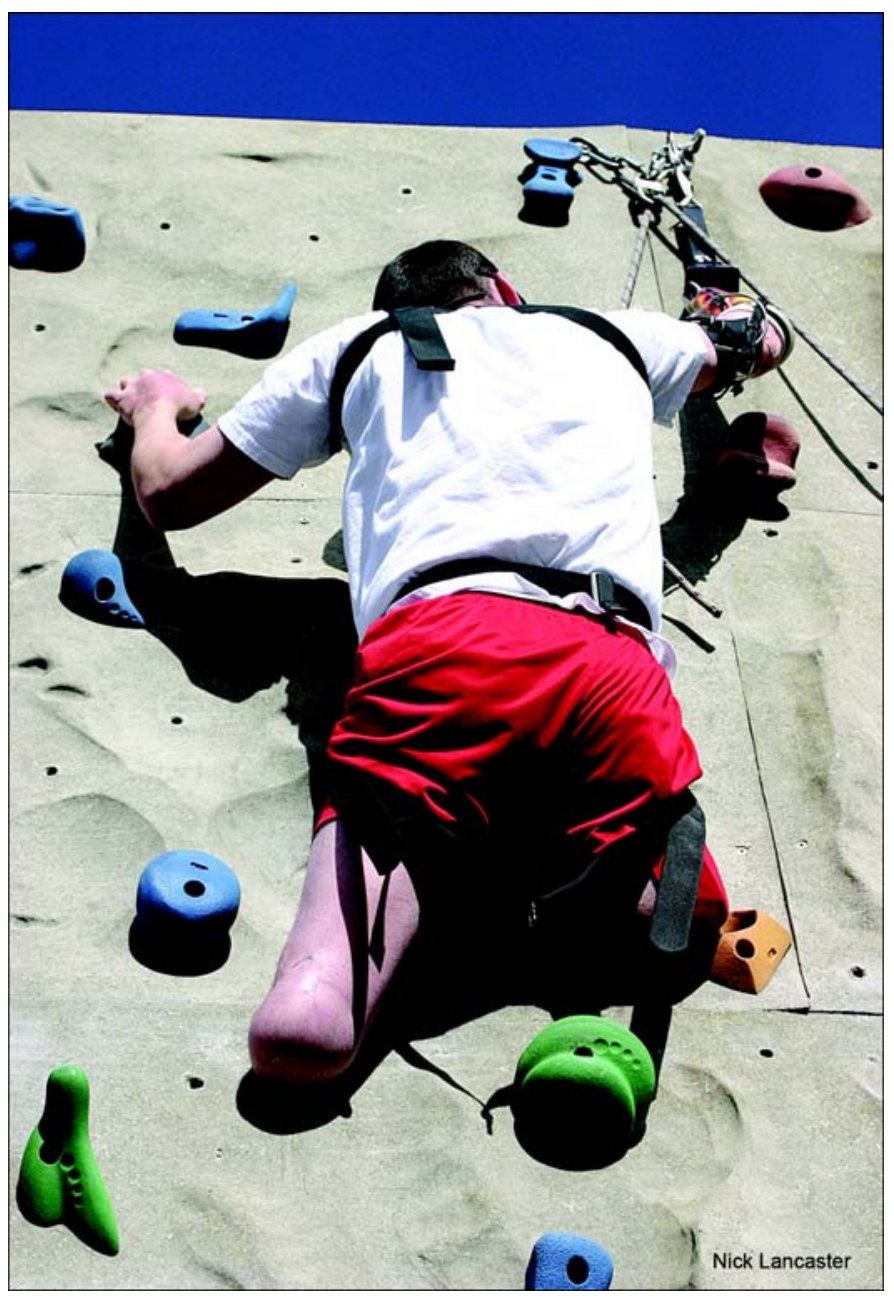

remain, each year participants are organized and moved through scheduled activities with ease in a seamless fashion and given the opportunity to experience one of the most challenging and rewarding weeks of their lives.

This year, the National Disabled Veterans Winter Sports Clinic celebrates its 20th anniversary and continues to prove skeptics wrong. Thanks to the continued support of its cosponsors, the VA and the Disabled American Veterans, as well as the tireless dedication of all the generous corporate sponsors and unselfish volunteers, the clinic will be a success for many years to come and continue to change the lives of disabled veterans and help shape the perception the public has of individuals with disabilities.

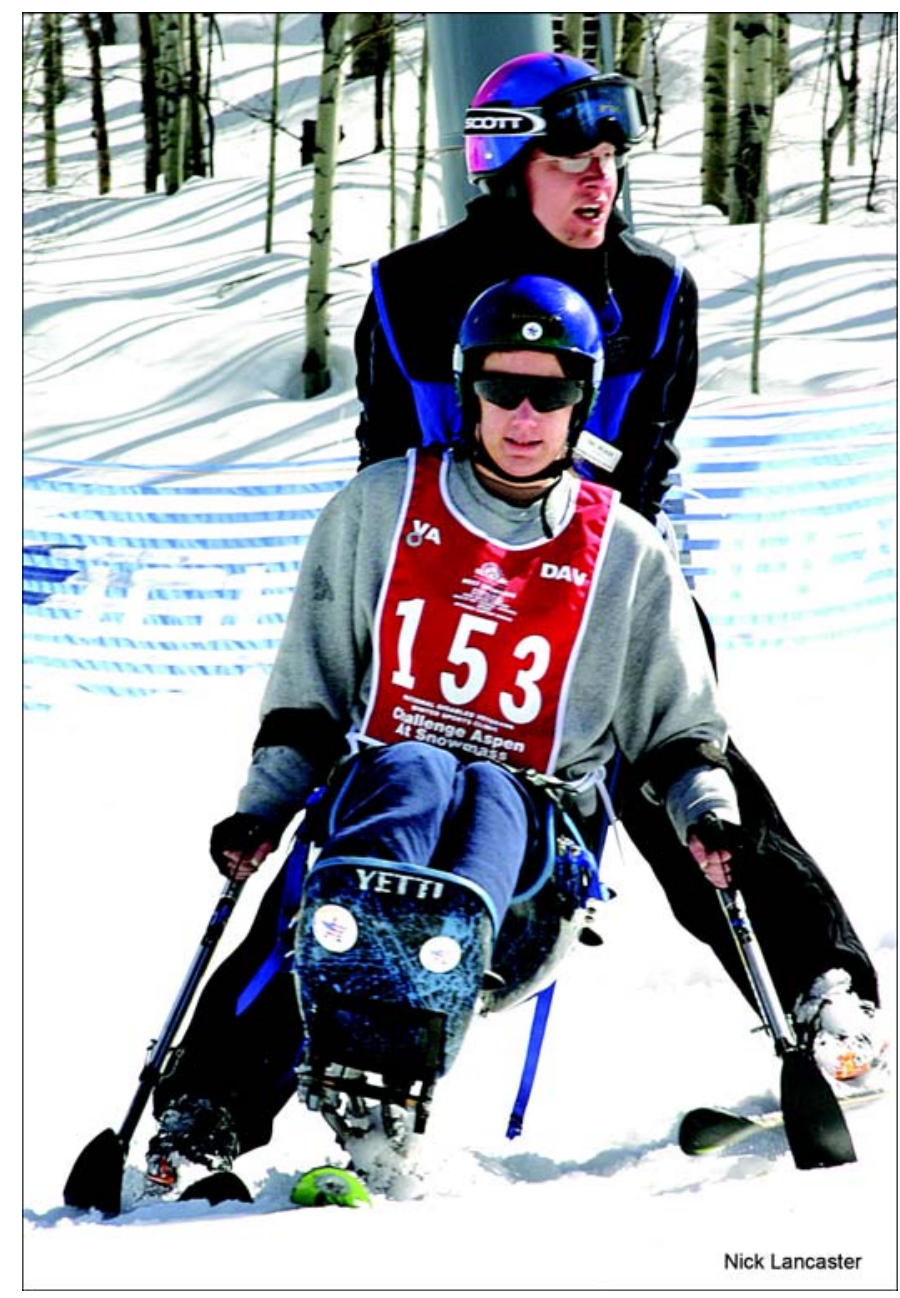

\section{REFERENCES}

1. Ratner RE, The Diabetes Prevention Program Research. An update on the Diabetes Prevention Program. Endocr Pract. 2006;12 Suppl 1:20-24. [PMID: 16627375]

2. Pinto A, Di Raimondo D, Tuttolomondo A, Fernandez P, Arna V, Licata G. Twenty-four hour ambulatory blood pressure monitoring to evaluate effects on blood pressure of physical activity in hypertensive patients. Clin J Sport Med. 2006;16(3):238-43. [PMID: 16778545]

3. Myers DJ. The food industry's solution to the obesity epidemic: Take a walk. New Solut. 2006;16(1):13-16. [PMID: 16867888]

4. Taylor CB, Sallis JF, Needle R. The relation of physical activity and exercise to mental health. Public Health Rep. 1985;100(2):195-202. [PMID: 3920718$]$ 
5. Hicks AL, Martin KA, Ditor DS, Latimer AE, Craven C, Bugaresti J, McCartney N. Long-term exercise training in persons with spinal cord injury: Effects on strength, arm ergometry performance and psychological well-being. Spinal Cord. 2003;41(1):34-43.

[PMID: 12494319]

6. Allegretti A, Fitzgerald S, Cooper R, Collins D, Martin $S$. The relationship between pain, fatigue and level of depression in wheelchair users. RESNA 26th International Annual Conference Proceedings; 2004 Jun 19-23; Atlanta, GA. Arlington (VA): RESNA; 2004.

7. Paulsen P, French R, Sherrill C. Comparison of wheelchair athletes and nonathletes on selected mood states. Percept Mot Skills. 1990;71(3 Pt 2):1160-62.

[PMID: 2150880]
8. Cooper RA, O’Conner TJ, Robertson RN, Langbein WE, Baldini FD. An investigation of the exercise capacity of the wheelchair sports USA team. Assist Technol. 1999;11(1):34-42.

9. International Paralympic Committee. Spirit in motion; 2003. Bonn (Germany): International Paralympic Committee; 2003. p. 1-9.

\section{Paul F. Pasquina, MD}

Lieutenant Colonel, U.S. Army Medical Corps;

Chief, Physical Medicine \& Rehabilitation, Medical Director, Amputee Program, Walter Reed Army

Medical Center, Washington, DC

Email:paul.pasquina@na.amedd.army.mil

DOI: 10.1682/JRRD.2006.08.0099 